\title{
OPTIMIZATION OF BIODIESEL PRODUCTION FROM WASTE FRYING OIL OVER ALUMINA SUPPORTED CHICKEN EGGSHELL CATALYST USING EXPERIMENTAL DESIGN TOOL
}

\author{
Adeyinka S. YusufF*, Lekan T. Popoola \\ Department of Chemical and Petroleum Engineering, College of Engineering, Afe Babalola University, \\ Ado-Ekiti, Nigeria \\ * corresponding author: yusuffas@abuad.edu.ng
}

\begin{abstract}
An optimization of the biodiesel production from a waste frying oil via a heterogeneous transesterification was studied. This present study is also aimed at investigating the catalytic behaviour of the alumina supported eggshell (ASE) for the synthesis of biodiesel. A synthesized ASE catalyst, at various mixing ratios of alumina to eggshell, was investigated and exhibited a better activity for the reaction when the eggshell and alumina were mixed via incipient wetness impregnation in $2: 1$ proportion on a mass basis and calcined at $900{ }^{\circ} \mathrm{C}$ for $4 \mathrm{~h}$. The as-synthesized catalyst was characterized by basicity, BET, SEM, EDX, and FTIR. The $2^{k}$ factorial experimental design was employed for an optimization of process variables, which include catalyst loading, reaction time, methanol/oil molar ratio and reaction temperature and their effects on the biodiesel yield were studied. The optimization results showed that the reaction time has the highest percentage contribution of $40.139 \%$ while the catalyst loading contributes the least to the biodiesel production, as low as $1.233 \%$. The analysis of variance (ANOVA) revealed a high correlation coefficient $\left(R^{2}=0.9492\right)$ and the interaction between the reaction time and reaction temperature contributes significantly to the biodiesel production process with percentage contribution of $14.001 \%$, compared to other interaction terms. The biodiesel yield of $77.56 \%$ was obtained under the optimized factor combination of $4.0 \mathrm{wt}$.\% catalyst loading, $120 \mathrm{~min}$ reaction time, $12: 1$ methanol/oil molar ratio and reaction temperature of $65^{\circ} \mathrm{C}$. The reusability study showed that the ASE catalyst could be reused for up to four cycles and the biodiesel produced under optimum conditions conformed to the ASTM standard.
\end{abstract}

KEYWORDS: biodiesel; catalyst; characterization; eggshell; waste frying oil.

\section{INTRODUCTION}

Biodiesel is a biogenic, renewable, non-toxic and esterderived oxygenated fuel. It is commonly produced from animal fat, edible (soybean, palm, coconut, corn) oil, non-edible (cotton seed, Jatropha curcas, algae, sunflower) oil and waste vegetable oil. According to Tan et al. 14, biodiesel can conveniently be used to power a diesel engine without making any adjustment to the engine. Besides, it is energy efficient, environmentally friendly and reduces the greenhouse gases emission [15]. However, the exorbitant cost of biodiesel has been a major reason why its production has not been largely commercialized. Two ways in which this problem could be addressed according to Fabbri et al. [2] and Taufiq-yap et al. [15] include a biodiesel synthesis from a waste vegetable or nonedible oil and the use of solid catalysts derived from readily available waste or naturally occurring materials instead of a homogeneous catalyst and enzyme.

Generally, biodiesel, a form of mono-alkyl ester, is commonly produced via transesterification of oil with alcohol (methanol, ethanol, propanol and butanol) in the presence of a catalyst. Glycerol is also formed as a by-product. Transesterification is an organic reaction in which an ester is transformed into another through an interchange of the special functional group called alkoxy moiety [12]. Typically, methanol is used as the co-reactant for the conversion of triglyceride to produce fatty acid methyl ester (biodiesel), because it is relatively cheap, readily available and easier to separate than glycerol from the product mixture [13. The reaction is illustrated by the overall equation given in Figure 1 .

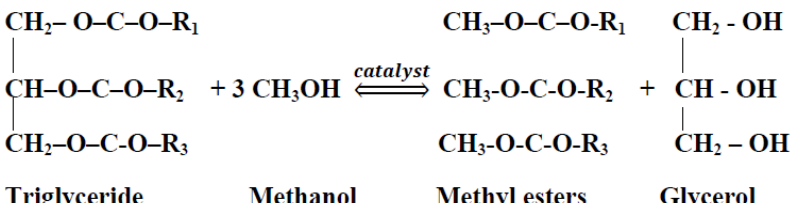

FiguRE 1. Transesterification of glyceride with methanol.

The current biodiesel production process involves the use of a homogenous catalyst, such as $\mathrm{NaOH}, \mathrm{HCl}$, $\mathrm{KOH}$ and $\mathrm{H}_{2} \mathrm{SO}_{4}$. However, there are some problems associated with the homogeneous catalysed transesterification process, that is, the generation of wastewater and non-reusability of liquid catalysts. According to Taufiq-yap et al. [15], the use of heterogeneous catalysts in transesterification reaction could reduce the 
costs of the biodiesel production. This is because; they are much easier to separate from the product mixture, reusable and do not generate wastewater. A heterogeneous catalyst could be classified into solid base and solid acid catalysts. Solid base catalysts are often used for a transesterification reaction. They do exhibit higher activity and proceed faster to equilibrium when compared to an acid heterogeneous catalyst. Besides, solid base catalysts could easily be synthesized from waste and naturally occurring materials. Nevertheless, the heterogeneous catalyst is well known for its mass transfer limitation, because it forms three phases with methanol and oil, thus lowering the reaction rate [7, 15]. However, the diffusion limitation could be overcome by using catalyst supports or promoters which can enhance the textural properties and basic strength of the catalyst. Besides, they firmly anchor the catalyst's active ingredient, thus minimizing the degree of leaching 4 . Several catalyst supports, such as alumina $\left(\mathrm{Al}_{2} \mathrm{O}_{3}\right)$, silica $\left(\mathrm{SiO}_{2}\right)$, zirconia $\left(\mathrm{ZrO}_{2}\right)$ and titania $\left(\mathrm{TiO}_{2}\right)$, have been used in a biodiesel production process [3, 5, 16. Among the aforementioned supports, alumina has been widely used for anchoring catalyst active ingredients due to its high thermal stability, better mechanical properties, and better textural characteristics [15. Taufiq-yap et al. [15] synthesized $\mathrm{NaOH} / \mathrm{Al}_{2} \mathrm{O}_{3}$ catalyst and used it for the production of biodiesel from palm oil. The maximum biodiesel yield of $99 \%$ was obtained under optimum reaction conditions. Umdu et al. [16], in their research work, used $\mathrm{Al}_{2} \mathrm{O}_{3} / \mathrm{CaO}$ as a heterogeneous catalyst in converting the lipid of microalgae to biodiesel. The biodiesel yield from the process was $80 \%$. Meanwhile, none of the previous researchers discussed had done a detailed work to check the performance of alumina when loaded on $\mathrm{CaO}$ derived from agricultural waste.

The use of low quality feedstock such as waste frying oil (WFO) to synthesize biodiesel will reduce the production cost. Therefore, the current study is focused on the use of alumina supported eggshell as a heterogeneous base catalyst for the transesterification of WFO with methanol because of the easy availability of both reactants. Also, the 2-level factorial design of the experiment was applied to the optimization of the biodiesel production process. The variables (factors) considered were the reaction temperature, reaction time, catalyst loading and methanol/WFO molar ratio.

\section{Materials And Method}

\subsection{MATERIALS}

In this current study, the WFO and waste chicken eggshells were collected from the cafeteria of Afe Babalola University, Ado-Ekiti, Nigeria. The oil was first heated in an oven at $150{ }^{\circ} \mathrm{C}$ for $3 \mathrm{~h}$ to reduce the moisture content and later filtered using a $100 \mu \mathrm{m}$ sieve mesh to remove bits of food residues. The acid value and free fatty acid (FFA) of the oil were determined to be $3.847 \mathrm{mgKOH} / \mathrm{g}$ and $1.924 \mathrm{wt} . \%$, respectively. However, since the FFA content of the WFO is less than $3.0 \mathrm{wt} . \%$, the single step transesterification process is appropriate to convert the oil to biodiesel [14. Methanol $\left(\mathrm{CH}_{3} \mathrm{OH}, 99.5 \%\right.$ synthesis grade) was used as a co-reactant for the transesterification and gamma alumina (anhydrous $\mathrm{Al}_{2} \mathrm{O}_{3}$ ) was used as a catalyst support. These compounds were procured from Topjay chemical enterprise, Ado-Ekiti, Nigeria and employed as received without subjecting them to a further purification.

\subsection{Preparation of the Catalyst}

The waste chicken eggshells were initially soaked and thoroughly washed with clean water to remove all attached dirt. The cleaned eggshells were thereafter heated up in an oven at $125^{\circ} \mathrm{C}$ until the water was completely dried up. The dried eggshell was later crushed into a powder by mechanical grinder and the powder obtained was allowed to pass through $0.3 \mathrm{~mm}$ sieve mesh to obtain a fine powder with particle size lesser than $0.3 \mathrm{~mm}$. It was then kept in a sealed plastic container.

The procedure used to prepare the supported catalyst was referred in our previous work [19]. Three different samples of alumina supported eggshell catalyst were prepared by weighing and mixing the prepared eggshell powder and alumina in $1: 1,2: 1$ and $1: 2$ mass ratios of eggshell to alumina. The resulting mixtures were dissolved in $50 \mathrm{~mL}$ of distilled water to form suspensions and stirred continuously until the mixtures were homogenous. The obtained slurries were then heated up in an oven at $110^{\circ} \mathrm{C}$ to remove the water. Thereafter, the three dried samples were calcined in a muffle furnace at $900^{\circ} \mathrm{C}$ for $4 \mathrm{~h}$. The calcined catalysts were kept in a desiccator containing silica particles in order to prevent atmospheric moisture and carbon dioxide that might be in contact with the catalysts.

\subsection{Characterization of the Prepared Catalysts}

The textural features of the prepared catalyst samples were determined by Brunauer-Emmett-Teller (BET) technique using micrometrics analyser (Quantachrome instrument, Nova station A, version 11.03, USA) based on the principle of adsorption/desorption of nitrogen at $77 \mathrm{~K}$ and $60 / 60 \mathrm{sec}$ (ads/des) equilibrium time. The basicity of the as-synthesized catalysts was determined by a colorimetric titration method reported by Abdoulmoumine [1]. Scanning electron microscope-energy dispersive X-ray (SEM-EDX) analyser (JEOL-JSM $7600 \mathrm{~F}$ ) was used simultaneously to determine the surface morphology and elemental composition of the prepared catalysts, while Fourier transform infrared (FTIR) spectrophotometer (IR Affinity 1S, Shimadzu, Japan) was employed to determine the surface functional groups on the as-synthesized catalysts. 


\begin{tabular}{cccc}
\hline Eggshell/ $\mathrm{Al}_{2} \mathrm{O}_{3}$ ratio & \multicolumn{2}{c}{ Textural properties } & $\begin{array}{c}\text { Basicity } \\
\text { (mmol/g cat })\end{array}$ \\
\cline { 2 - 3 } & BET area $\left(\mathrm{m}^{2} / \mathrm{g}\right)$ & Total pore volume $\left(\mathrm{cm}^{3} / \mathrm{g}\right)$ & 1.34 \\
\hline $1: 1$ eggshell loading on $\mathrm{Al}_{2} \mathrm{O}_{3}$ & 49.6 & 0.117 & 1.88 \\
2: 1 eggshell loading on $\mathrm{Al}_{2} \mathrm{O}_{3}$ & 78.2 & 0.341 & 0.58 \\
$1: 2$ eggshell loading on $\mathrm{Al}_{2} \mathrm{O}_{3}$ & 60.9 & 0.281 & \\
\hline
\end{tabular}

TABLE 2. Textural properties and basicity of the different ratio of prepared alumina supported eggshell catalysts.

\begin{tabular}{lcc}
\hline \multicolumn{1}{c}{ Variable } & \multicolumn{2}{c}{ Level } \\
\cline { 2 - 3 } & low & high \\
& $(-1)$ & $(+1)$ \\
\hline Reaction temperature $(T)$ & $50{ }^{\circ} \mathrm{C}$ & $65{ }^{\circ} \mathrm{C}$ \\
Reaction time $(t)$ & $1 \mathrm{~h}$ & $2 \mathrm{~h}$ \\
Catalyst loading $(C)$ & $2 \mathrm{wt} . \%$ & $4 \mathrm{wt} . \%$ \\
Methanol/WFO ratio $(M)$ & $6: 1$ & $12: 1$ \\
\hline
\end{tabular}

TABLE 1. Studied range of each variable in actual and coded form.

\subsection{The $2^{k}$ FACtorial Experimental DESIGN}

A factorial method of an analysis is one of the numerous features of the design of an experiment used in studying the influence of an individual variable and its interaction with other variables. It economizes the experimental resources by reducing the number of runs [1]. In this study, four process independent variables, which include reaction temperature, reaction time, catalyst loading and methanol/WFO molar ratio, were of interest, with biodiesel yield as the response. However, the response was determined via the transesterification process with the aim to identify the optimum reaction condition that would provide a maximum biodiesel yield. A total of sixteen (16) experimental runs were conducted according to a $2^{k}$ factorial design with the four process variables $\left(2^{4}=16\right.$ points). Table 1 presents the experimental design matrix for a $2^{4}$ factorial design.

\subsection{Transesterification Reaction Study}

The transesterification of the WFO to biodiesel using a calcined alumina supported eggshell catalyst was conducted according to experimental design values (Table 1) and the response measured was the yield of biodiesel. The whole experiments were performed in a $250 \mathrm{~mL}$ glass reactor placed on a temperature controlled heating mantle. Fifty grams $(50 \mathrm{~g})$ of the WFO were heated up to a desired temperature in an oven, after which the mixture of methanol and catalyst with a required amount was added to the heated oil. The reaction mixture was stirred with a speed of $350 \mathrm{rpm}$. After the reaction was completed, the catalyst was separated from the product mixture (biodiesel and glycerol) by a cloth filtration. The yield of biodiesel collected from the product mixture was then evaluated as [6]

$$
\text { Biodiesel yield, } Y=\frac{\text { weight of biodiesel }}{\text { weight of WFO used }} \cdot 100 \% \text {. }
$$

\subsection{BIODIESEL PRODUCT ANALYSIS}

The synthesized biodiesel was characterized for a specific gravity, kinematic viscosity, cloud point, pour point and flash point and was compared with ASTM D6571 standard method. The quality of the WFO biodiesel was further ascertained by the FTIR spectrophotometer (IR Affinity 1S, Shimadzu, Japan) in which the functional groups contained in it were determined. Moreover, a gas chromatography-mass spectrometry (Hewlett Packard 6890S, Palo Alto, USA) analysis was conducted on the biodiesel product to determine the type of the formed methyl esters.

\subsection{Catalyst Reusability Study}

The reusability of the supported catalyst was conducted in order to check its stability after reuse. The used catalyst was collected from the product mixture after the completion of the transesterification reaction, washed severally with methanol to remove oil that was attached to the catalyst particles and heated up at $60^{\circ} \mathrm{C}$ in an oven until it dried out. Thereafter, the dried catalyst sample was recalcined in a muffle furnace at $700{ }^{\circ} \mathrm{C}$ for $2 \mathrm{~h}$. The recalcined catalyst was weighed and reused for subsequent reactions at the same operating conditions. After a fourth cycle, the reaction was discontinued because of the quantity of the recovered catalyst, which was significantly reduced.

\section{Results And Discussion}

\subsection{Characterization of the Catalyst}

The textural characteristics and basicity of the three prepared catalyst samples were determined. According to the results depicted in Table 2, it was found that the catalyst sample with the eggshell $/ \mathrm{Al}_{2} \mathrm{O}_{3}$ mass ratio of $2: 1$ exhibited better textural properties and strong basic strength. This is attributed to the fact that the catalyst sample contains a larger proportion of eggshell, which decomposed into $\mathrm{CaO}$ and $\mathrm{CO}_{2}$ after calcination [14] and amphoteric nature of $\mathrm{Al}_{2} \mathrm{O}_{3}$. According to Olutoye and Hameed [8], the oxygen atoms contained in the $\mathrm{CaO}$ and $\mathrm{Al}_{2} \mathrm{O}_{3}$ signify Lewis base sites while the metal ions represent 

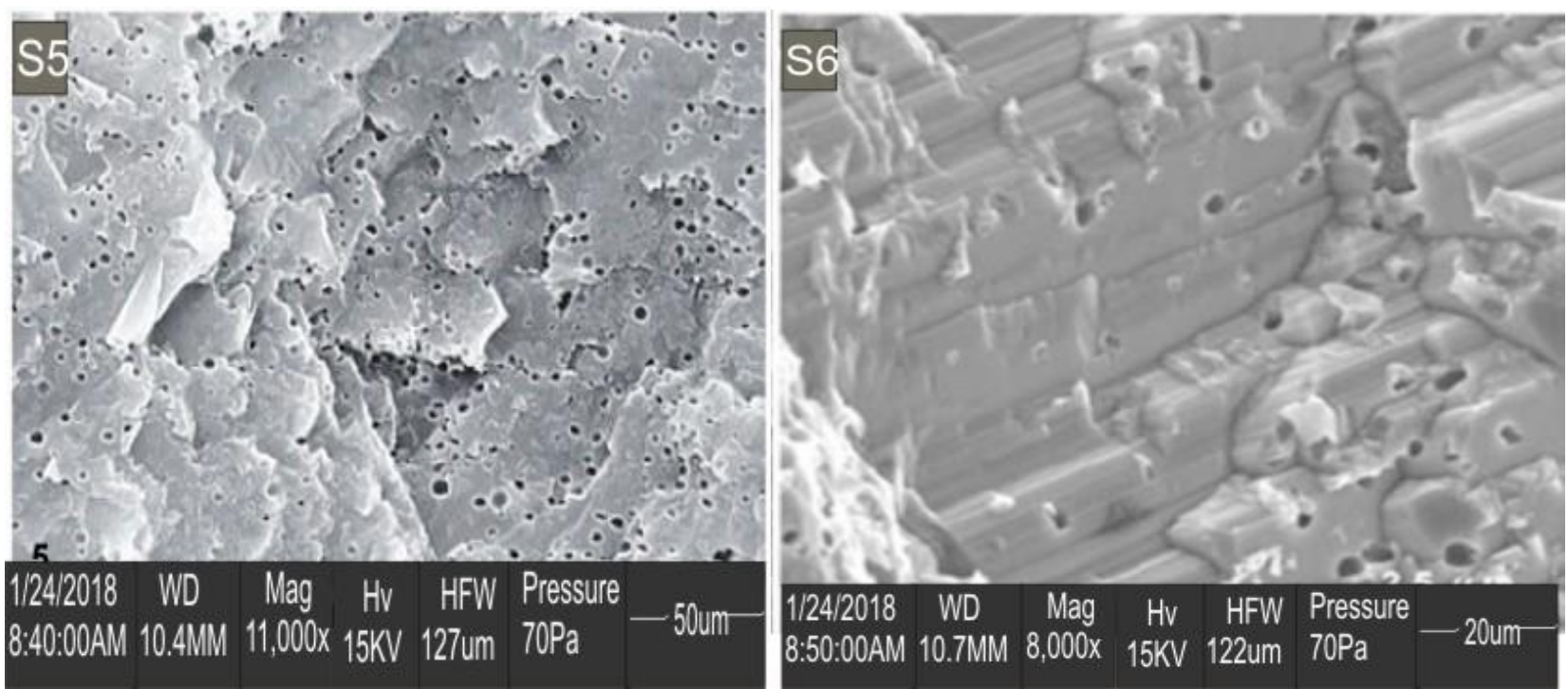

FIGURE 2. SEM images of (left) raw; (right) calcined ASE catalyst

Lewis acid sites. Thus, the high basicity possessed by this sample implied that the Lewis base sites are active centres for the transesterification reaction. This is corroborated by the EDX analysis. In addition, higher values of surface area $\left(78.2 \mathrm{~m}^{2} / \mathrm{g}\right)$ and total pore volume $\left(0.341 \mathrm{~cm}^{3} / \mathrm{g}\right)$ recorded for this same catalyst sample indicate that the catalyst external surface is dominated by active sites and it can eliminate the mass transfer limitation, leading to a faster reaction process [14. Having identified the prepared catalyst with the ratio $2: 1$ of eggshell loading onto $\mathrm{Al}_{2} \mathrm{O}_{3}$ as the most active sample amongst other synthesized catalysts, it was further characterized and studied in details under various operating reaction conditions.

The SEM analysis was conducted in order to examine the external morphology of raw and calcined ASE catalysts using a very large magnification. The SEM images of the catalysts, presented in Figure 2 Figure 2(left) showed that the raw catalyst possessed an undefined structure with various tiny pores on its surface. This observation might be attributed to the method of preparation adopted. However, upon calcination, several large pores of different sizes were clearly seen on the catalyst's surface as shown in Figure 2 (right). This observation could be attributed to the decomposition of $\mathrm{CaCO}_{3}$ contained in eggshell into $\mathrm{CaO}$ and $\mathrm{CO}_{2}$. The SEM result of the calcined ASE catalyst also showed that an elevated calcination temperature facilitated a removal of adsorbed gases, organic matters, moisture and surface and bulk atom rearrangement, thus leading to pore creation and basic sites exposure on the catalyst's surface [12].

The elemental composition analysis of the ASE catalyst (Table 3) showed that it contained calcium, oxygen, carbon, aluminium and magnesium. The

\begin{tabular}{lcc}
\hline \multirow{2}{*}{ Element } & \multicolumn{2}{c}{ ASE catalyst sample } \\
\cline { 2 - 3 } & Raw & Calcined \\
\hline Calcium & 48.8 & 65.9 \\
Carbon & 26 & 4.6 \\
Aluminum & 10.8 & 10.6 \\
Magnesium & 4.2 & 2.7 \\
Oxygen & 10.4 & 16.1 \\
\hline
\end{tabular}

TABLE 3. Elemental analysis for raw and calcined ASE catalysts.

composition of the calcium and oxygen in the raw catalyst were $48.8 \mathrm{wt} . \%$ and $10.4 \mathrm{wt} . \%$ respectively, but they increased to $65.9 \mathrm{wt} . \%$ and $16.1 \mathrm{wt} . \%$ respectively after the calcination. However, the composition of all other elements was reduced after the thermal treatment. The increase in calcium content after the calcination was due to the decomposition of $\mathrm{CaCO}_{3}$ in eggshell. A similar observation was reported by Tan et al. 14 in the transesterification of a waste cooking oil using calcined ostrich and chicken eggshells as the catalysts.

The FTIR spectrum of a raw ASE catalyst is shown in Figure 3(a) with various adsorption bands at $3436.56 \mathrm{~cm}^{-1}$ (N-H stretch), $2874.03 \mathrm{~cm}^{-1}$ (CH antisymmetric stretch), $2515.26 \mathrm{~cm}^{-1}(\mathrm{O}-\mathrm{H}$ stretch), $2360.95 \mathrm{~cm}^{-1}(\mathrm{~N}-\mathrm{H}$ stretch $), 1797.72 \mathrm{~cm}^{-1} \quad(\mathrm{C}=\mathrm{O}$ antisymmetric stretch), $1421.58 \mathrm{~cm}^{-1}$ (in-plane $\mathrm{OH}$ bend), $875.71 \mathrm{~cm}^{-1}$ (CH out-of-plane deformation) and $455.22 \mathrm{~cm}^{-1}(\mathrm{C}-\mathrm{N}-\mathrm{C}$ bend). These surface functional groups are an indication that the ASE catalyst is complex in nature. However, upon calcination, some peaks were shifted or vanished and new bands at $3643.65 \mathrm{~cm}^{-1}(\mathrm{O}-\mathrm{H}$ stretch $), 1626.05 \mathrm{~cm}^{-1}(\mathrm{C}=\mathrm{O}$ stretch), $1413.87 \mathrm{~cm}^{-1}$ (C-N stretch), $1022.31 \mathrm{~cm}^{-1}$ 


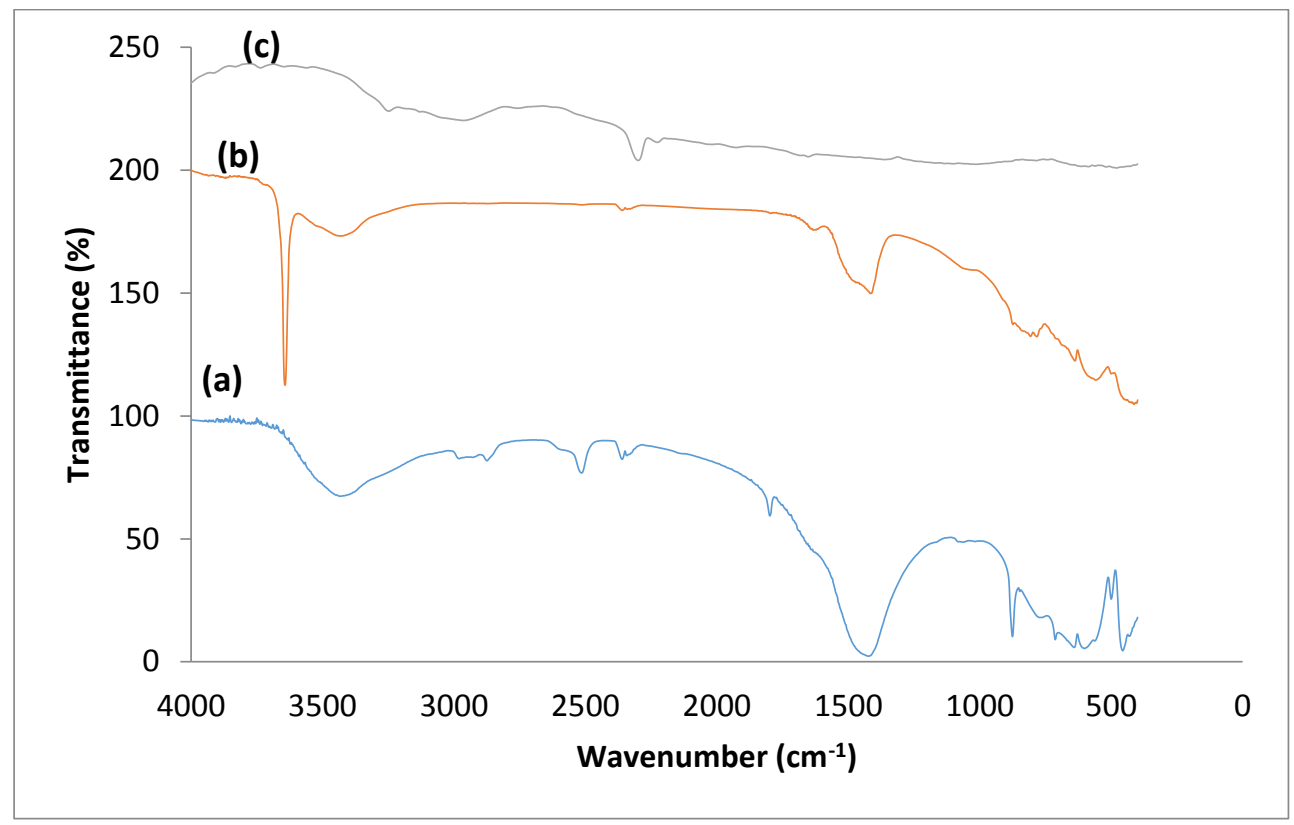

FiguRE 3. FTIR spectra of (a) raw, (b) calcined and (c) reused ASE catalysts.

\begin{tabular}{|c|c|c|c|c|c|c|}
\hline \multirow[t]{2}{*}{ Run } & \multicolumn{4}{|c|}{ Transesterification process variable } & \multicolumn{2}{|c|}{ Biodiesel yield, $Y(\%)$} \\
\hline & $\begin{array}{l}\text { Catalyst } \\
\text { loading } \\
C \text { (wt.\%) }\end{array}$ & $\begin{array}{c}\text { Reaction } \\
\text { time } \\
t(\min )\end{array}$ & $\begin{array}{c}\text { Methanol/oil } \\
\text { ratio } \\
M\end{array}$ & $\begin{array}{c}\text { Reaction } \\
\text { temperature } \\
T\left({ }^{\circ} \mathrm{C}\right)\end{array}$ & Experimental & Predicted \\
\hline 1 & 2 & 60 & 6 & 50 & 45.46 & 42.33 \\
\hline 2 & 4 & 60 & 6 & 50 & 27.66 & 31.30 \\
\hline 3 & 2 & 120 & 6 & 50 & 57.28 & 60.41 \\
\hline 4 & 4 & 120 & 6 & 50 & 59.09 & 55.44 \\
\hline 5 & 2 & 60 & 12 & 50 & 31.32 & 34.39 \\
\hline 6 & 4 & 60 & 12 & 50 & 38.13 & 34.54 \\
\hline 7 & 2 & 120 & 12 & 50 & 68.45 & 65.38 \\
\hline 8 & 4 & 120 & 12 & 50 & 68.00 & 71.59 \\
\hline 9 & 2 & 60 & 6 & 65 & 47.19 & 44.03 \\
\hline 10 & 4 & 60 & 6 & 65 & 41.23 & 43.87 \\
\hline 11 & 2 & 120 & 6 & 65 & 38.48 & 41.64 \\
\hline 12 & 4 & 120 & 6 & 65 & 50.18 & 47.54 \\
\hline 13 & 2 & 60 & 12 & 65 & 48.36 & 51.58 \\
\hline 14 & 4 & 60 & 12 & 65 & 61.32 & 62.62 \\
\hline 15 & 2 & 120 & 12 & 65 & 65.32 & 62.10 \\
\hline 16 & 4 & 120 & 12 & 65 & 76.50 & 79.20 \\
\hline
\end{tabular}

TABLE 4. Factorial design for transesterification process variables.

$(\mathrm{P}-\mathrm{O}-\mathrm{C}$ antisymmetric stretch $), 783.13 \mathrm{~cm}^{-1}(\mathrm{CH}$ out-of-plane deformation) and $559.38 \mathrm{~cm}^{-1}(\mathrm{C}-\mathrm{C}=\mathrm{O}$ bend) were detected as shown in Figure 3(b). In the case of a reused catalyst (Figure 3(c)), many of the absorption bands displayed by the calcined catalyst disappeared after the use and new bands $\left(3203.87 \mathrm{~cm}^{-1}\left(\mathrm{NH}_{2}\right.\right.$ symmetric stretch), $2893.32(\mathrm{CH}$ antisymmetric stretch) and $2278.01(\mathrm{~N}=\mathrm{C}=\mathrm{O}$ antisymmetric stretch)) were also detected. The presence of these functional groups contributes to the good activity of the catalyst [10].

\subsection{Statistical AnAlysis OF EXPERIMENTAL DATA}

The synthesis of biodiesel from the WFO in the presence of the ASE catalyst was carried out using a $2^{k}$ factorial experimental design as shown in Table 4 As can be seen, sixteen (16) experimental runs were conducted at different levels of independent variables considered.

It was revealed that the run 16 , which was conducted at $4.0 \mathrm{wt} . \%$ catalyst loading, $120 \mathrm{~min}$ reaction time, 12 : 1 methanol/oil molar ratio and $65^{\circ} \mathrm{C}$ re- 


\begin{tabular}{cccccc}
\hline Source & Sum of squares & Degree of freedom & Mean square & $F$-value & $p$-value $(\operatorname{Pr}>F)$ \\
\hline Model & 2992.54 & 10 & 299.25 & 9.35 & 0.0118 \\
$C$ & 36.75 & 1 & 36.75 & 1.15 & 0.3329 \\
$t$ & 1201.14 & 1 & 1201.14 & 37.53 & 0.0017 \\
$M$ & 562.05 & 1 & 562.05 & 17.56 & 0.0086 \\
$T$ & 86.44 & 1 & 86.44 & 2.70 & 0.1612 \\
\hline$C t$ & 36.69 & 1 & 36.69 & 1.15 & 0.3332 \\
$C M$ & 125.16 & 1 & 125.16 & 3.91 & 0.1049 \\
$C T$ & 118.32 & 1 & 118.32 & 3.70 & 0.1125 \\
$t M$ & 166.73 & 1 & 166.73 & 5.21 & 0.0713 \\
$t T$ & 418.92 & 1 & 418.92 & 13.09 & 0.0153 \\
$M T$ & 240.33 & 1 & 240.33 & 7.51 & 0.0408 \\
\hline Residual & 160.02 & 5 & 32 & - & - \\
\hline Cor. Total & 3125 & 15 & - & - & - \\
\hline$R^{2}=0.9492 ;$ Adj- $R^{2}=0.8477$ & & & &
\end{tabular}

TABLE 5. ANOVA analysis for $2^{k}$ factorial design.

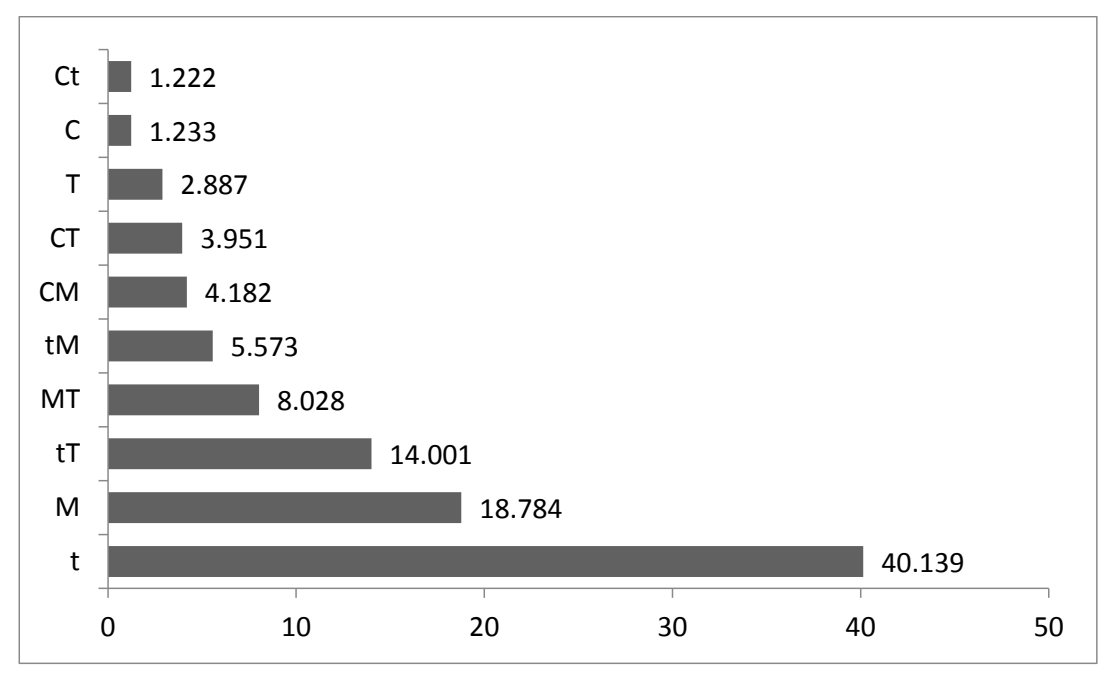

Figure 4. Pareto graphic analysis - percentage effect of each factor.

action temperature, gave the highest biodiesel yield with the value obtained to be $76.50 \%$. Meanwhile, the lowest biodiesel yield was provided by the run 2 , which was conducted at $4.0 \mathrm{wt} . \%$ catalyst loading, $60 \mathrm{~min}$ reaction time, $6: 1$ methanol/oil molar ratio and $50{ }^{\circ} \mathrm{C}$ reaction temperature. These observations imply that, at the maximum reaction time, methanol/oil molar ratio and reaction temperature, the yield of biodiesel was favoured irrespective of the quantity of catalyst consumed during the reaction [17. This fact is affirmed by the run 15 , which was carried out at $2.0 \mathrm{wt} . \%$ catalyst loading, $120 \mathrm{~min}$ reaction time, 12 : 1 methanol/oil molar ratio and $65{ }^{\circ} \mathrm{C}$ reaction temperature and gave a $65.32 \%$ biodiesel yield. The regression model, which correlates the dependent and independent variables in terms of coded factor gives

$$
\begin{array}{r}
Y=51.75+1.52 C+8.66 t+5.93 M+2.32 T \\
+1.51 C t+2.80 C M+2.72 C T+3.23 t M \\
-5.12 t T+3.88 M T,
\end{array}
$$

where $C, t, M$ and $T$ are the catalyst loading, reaction time, methanol/oil molar ratio and reaction temperature, respectively. These are the main effects. While $C t, C M, C T, t M, t T$ and $M T$ represent interaction effects.

\subsubsection{Analysis of VARIANCE FOR BIODIESEL YIELD}

The model adequacy was tested using an analysis of variance (ANOVA) and Table 5 represents the results of the ANOVA analysis for the $2^{k}$ factorial design. The model $F$-value of 9.35 with a probability value $(\mathrm{Pr}>F)$ of 0.0118 confirms the adequacy of the model. In addition, two linear terms ( $\mathrm{t}$ and $\mathrm{M}$ ) and two interactive terms ( $t T$ and $M T$ ) are the significant model terms. This is because their $p$-values $(\operatorname{Pr}>$ $F)$ are less than 0.0500 . According to the $R^{2}$ value (0.9492), the obtained model accounts for $94.92 \%$ of the total variation in the experimental biodiesel yield. 


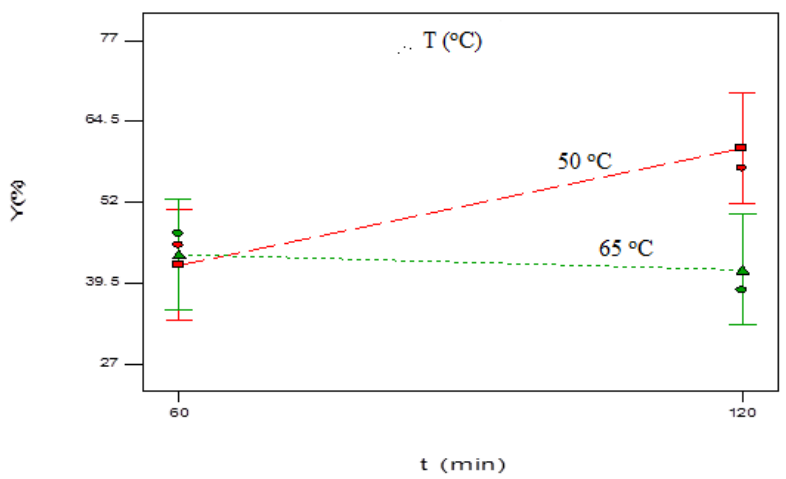

Figure 5. Plot of biodiesel yield $(Y)$ versus reaction time $(t)$ at reaction temperature of $50^{\circ} \mathrm{C}$ and $65^{\circ} \mathrm{C}$, 2 wt.\% catalyst loading and $6: 1$ methanol/oil molar ratio

\subsubsection{Analysis of Main Effects}

The contribution of each of the factors studied to the biodiesel production from the WFO is displayed in Figure 4 It was revealed that the reaction time contributes significantly to the yield of biodiesel, as much as $40.139 \%$. This implies that increasing the reaction time from $60 \mathrm{~min}$ to $120 \mathrm{~min}$ affects the biodiesel yield. The influence of the reaction time on biodiesel production process is widely reported [8, 14]. Yee and Lee [17] reported that, for the transesterification to occur and proceed to completion, higher reaction time and excess methanol are necessary. Since the reaction temperatures considered in this study are within the boiling point of methanol, longer reaction period favours the biodiesel yield. This is corroborated by the value of the biodiesel yield provided by the run 16, which was conducted for $120 \mathrm{~min}$ (Table 4).

The Methanol/oil molar ratio is the second factor that favours the biodiesel yield with the percentage contribution of $18.784 \%$ as shown in Figure 4 Two different methanol/oil molar ratios $(6: 1$ and 12 : 1) were considered in this study and the maximum molar ratio was found to have a positive effect on the biodiesel yield as confirmed in most of the runs such as run $7,8,13,14,15$ and 16 . Meanwhile, the use of excess methanol inhibited the separation of biodiesel from the product mixtures, thus reducing the biodiesel yield in some runs like runs 5 and 6 . This observation is similar to the one reported by Paintsil [11] who investigated the optimization of the biodiesel production from canola oil.

Furthermore, the third most influential factor is the reaction temperature, which contributes by $2.887 \%$ to the biodiesel production process as shown in Figure 4. The reason for this observation could be that the heterogeneous catalysed transesterification reaction often requires either a relatively high reaction temperature or high reaction time in order to achieve a greater biodiesel yield [17]. Since the yield of biodiesel was favoured by a high reaction period as it is the case in this study, the reaction temperature did not have a significant effect on the biodiesel production.

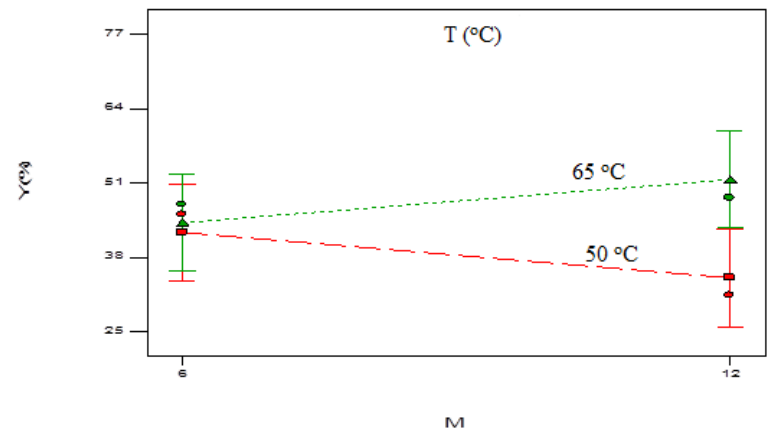

Figure 6. Plot of biodiesel yield (Y) versus methanol/oil molar ratio (M) at reaction temperature of $50^{\circ} \mathrm{C}$ and $65^{\circ} \mathrm{C}, 2$ wt. $\%$ catalyst loading and $60 \mathrm{~min}$ reaction time.

The catalyst loading contributes the least to the biodiesel production process, as low as $1.233 \%$ according to the Pareto graphic analysis shown in Figure 4. In this current study, the catalytic reaction was conducted at two different catalyst loadings (2.0 wt.\% and $4.0 \mathrm{wt} . \%)$. At a high catalyst loading of $4 \mathrm{wt} . \%$, a higher biodiesel yield was achieved. This is because enough active sites were available for the reaction and thus enhancing the intimacy between the catalyst and the reactants [14. Meanwhile, at a low catalyst loading, there was a decrease in the biodiesel yield, because the catalyst active sites were insufficient to promote the reaction to completion [20].

\subsubsection{ANALYSIS OF INTERACTION EFFECT.}

It was revealed from the ANOVA result that the interaction between process variables has a significant effect on the biodiesel yield. In this study, six interaction effect terms were displayed by the model (Table 5). Among these interactions, only MT and tT contributed significantly to the biodiesel production process with the percentage contribution of $8.028 \%$ and $14.001 \%$, respectively. Figure 5 depicts the plot of combined effects of the reaction time $(\mathrm{t})$ and reaction temperature $(\mathrm{T})$ on biodiesel yield $(\mathrm{Y})$ while keeping catalyst loading (C) and methanol/oil molar ratio (M) at 2 wt. $\%$ and $6: 1$, respectively. The plot revealed that, at $50{ }^{\circ} \mathrm{C}$ reaction temperature, maximum biodiesel yield could be achieved within $120 \mathrm{~min}$ compared to $60 \mathrm{~min}$. However, when the reaction was conducted at $65^{\circ} \mathrm{C}$, the biodiesel yield obtained in $60 \mathrm{~min}$ was greater than the one obtained in $120 \mathrm{~min}$. The former observation could be explained by the fact that at the lower temperature and higher reaction time, methanol did not dry up as the reaction temperature studied is less than the boiling point of methanol, which is around $65^{\circ} \mathrm{C}$ and as a result, the methanol was sufficient to drive the reaction forward.

The combined effects of the methanol/oil molar ratio and reaction temperature on the yield of biodiesel is depicted in Figure 6. When the reaction was conducted at a temperature of $65^{\circ} \mathrm{C}$, catalyst loading of $2 \mathrm{wt} . \%$ and $60 \mathrm{~min}$ reaction period, an increase in 


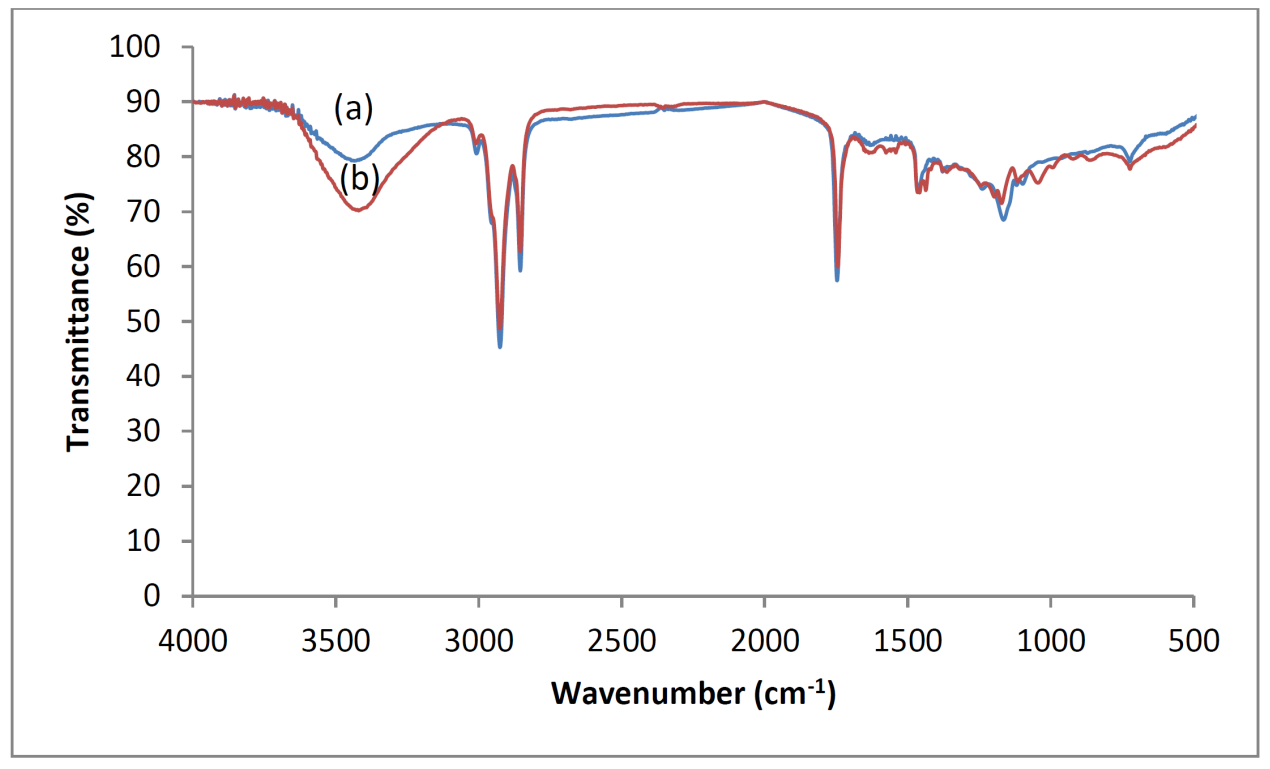

Figure 7. FTIR spectra of (a) WFO and (b) synthesized biodiesel.

\begin{tabular}{lcc}
\hline \multicolumn{1}{c}{ Property } & Value & ASTM D6571 \\
\hline Specific gravity & 0.879 & $0.86-0.90$ \\
Kinematic viscosity & $3.58 \mathrm{~mm}^{2} / \mathrm{s}$ & $1.9-6.0 \mathrm{~mm}^{2} / \mathrm{s}$ \\
Cloud point & $2^{\circ} \mathrm{C}$ & -3 to $15^{\circ} \mathrm{C}$ \\
Pour point & $-4.8^{\circ} \mathrm{C}$ & -5 to $10^{\circ} \mathrm{C}$ \\
Flash point & $145^{\circ} \mathrm{C}$ & $\geq 130^{\circ} \mathrm{C}$ \\
\hline
\end{tabular}

TABlE 6. Physico-chemical properties of WFO based biodiesel compared to ASTM (D6751) standards.

methanol/oil molar ratio resulted in an increase in the biodiesel yield. However, when the reaction was conducted at $50{ }^{\circ} \mathrm{C}$ for 60 min using $2 \mathrm{wt} . \%$ ASE catalyst dose, an increase in methanol/oil ratio was found to reduce the yield of biodiesel. The reduction in the biodiesel yield at a higher methanol/oil ratio is probably due to the dissolution of glycerol in methanol, which subsequently shifts the reaction backward [14].

\subsection{Numerical Optimization of Process Variables}

Having determined the optimum process variables for the production of biodiesel from the WFO using the ASE as a catalyst to be $4 \mathrm{wt} . \%, 120 \mathrm{~min}, 12: 1$ and $65{ }^{\circ} \mathrm{C}$ for catalyst loading, reaction time, methanol/oil molar ratio and reaction temperature, respectively, a further experimental run was conducted at these conditions and the experimental biodiesel yield was $77.56 \%$. However, the predicted biodiesel yield was calculated based on an empirical model developed by a design expert software and was found to be $79.20 \%$. This value is slightly greater than the actual value by $1.44 \%$. The result indicates that a maximum biodiesel yield can be achieved when the transesterification of the WFO over the ASE catalyst is conducted at the maximum values of variables studied.

\subsection{Catalyst Reusability Study}

The biodiesel yields for the four reaction cycles conducted under optimum conditions were $58.22 \%$, $42.71 \%, 29.88 \%$ and $18.92 \%$, respectively. The reason for the reduction in biodiesel yield is probably due to the saturation of the catalyst active sites by oil molecules. In addition, there was a loss of active sites during the catalyst regeneration process and as a result, there was a decrease in the biodiesel yield during reuse. This observation is similar to the one reported by Olutoye et al. [9].

\subsection{Analysis of Synthesized Biodiesel}

\subsubsection{Physicochemical Properties of Synthesized Biodiesel}

The properties of the prepared WFO based biodiesel, such as specific gravity, viscosity, cloud point, pour point and flash point, were determined and compared with ASTM D6571 standard as shown in Table 6.

\subsubsection{FTIR ANALYSIS}

The FTIR spectra of the WFO and its biodiesel are depicted in Figure 7. The spectra of the two substances are very similar because of the high degree of similarities between triglyceride and methyl ester [15]. Some of the peaks shifted after the conversion process. However, the adsorption bands at $2990-2850 \mathrm{~cm}^{-1}$ are assigned to $\mathrm{C}-\mathrm{H}$ antisymmetric and symmetric stretching. While the sharp peak at $1743.71 \mathrm{~cm}^{-1}$ is assigned to $\mathrm{C}=\mathrm{O}$ stretching mode of esters. The bands at $1155.20 \mathrm{~cm}^{-1}$ and $1026.16 \mathrm{~cm}^{-1}$ both correspond to $\mathrm{C}-\mathrm{O}$ stretching of esters. The absorption band at $1437.71 \mathrm{~cm}^{-1}$ can be attributed to the $\mathrm{CH}_{3}$ antisymmetric deformation. All these functional groups found in the prepared biodiesel confirmed the presence of methyl esters. 


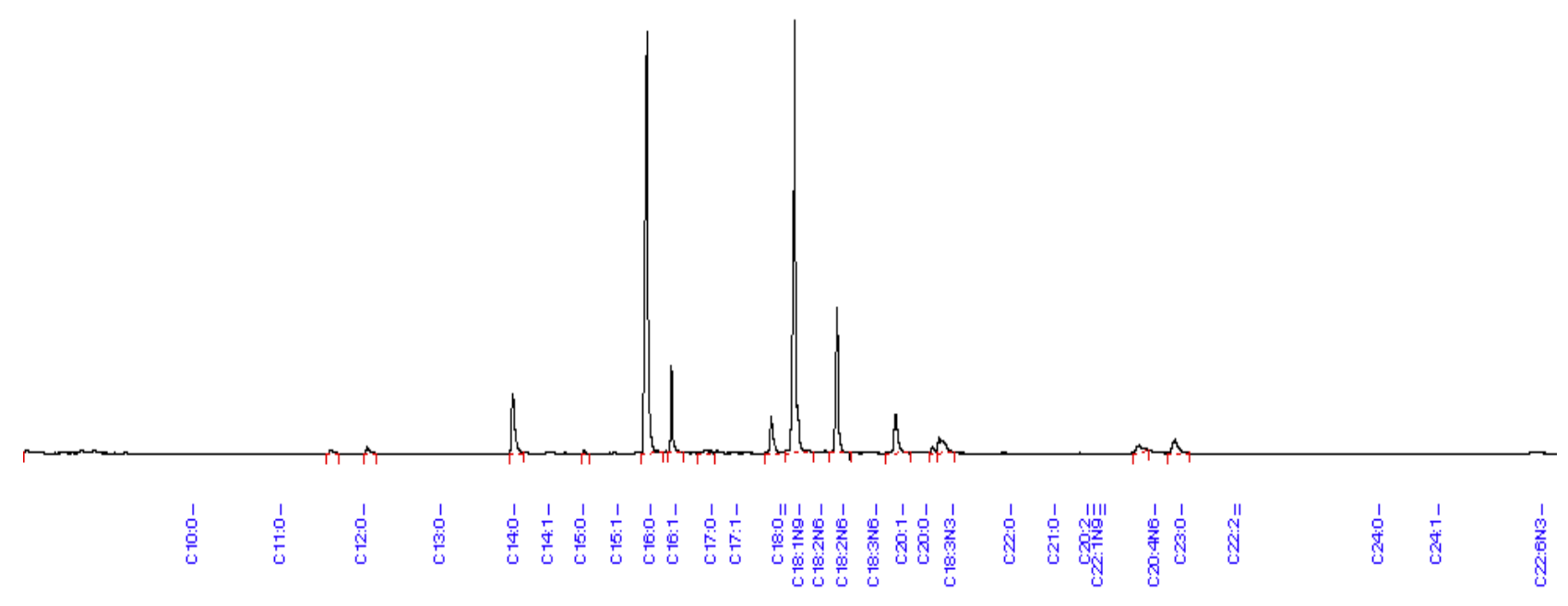

FIGURE 8. Result of GC-MS analysis on biodiesel synthesized under the optimized factor combination of 4.0 wt.\% catalyst loading, $120 \mathrm{~min}$ reaction time, $12: 1$ methanol/oil molar ratio and reaction temperature of $65^{\circ} \mathrm{C}$.

\begin{tabular}{lcc}
\hline \multicolumn{1}{c}{ Compound } & $\begin{array}{c}\text { Retention } \\
\text { time }(\min )\end{array}$ & $\begin{array}{c}\text { Concentra- } \\
\text { tion (wt.\%) }\end{array}$ \\
\hline Methyl palmitate & 38.36 & 33.33 \\
Methyl oleate & 46.87 & 41.01 \\
Methyl linoleate & 42.01 & 10.14 \\
Methyl palmitoleate & 47.81 & 4.24 \\
others & - & 7.17 \\
\hline
\end{tabular}

TABLE 7. Results of GC-MS analysis on biodiesel produced under optimum conditions.

\subsubsection{GC-MS ANALYSIS}

The chromatogram of the WFO biodiesel is depicted in Figure 8, which confirms the presence of methyl esters and Table 7 shows the description of the chromatograms. Both Figure 8 and Table 7 display the compositions of biodiesel from the transesterification of the WFO, which are mainly methyl palmitate, methyl oleate, methyl linoleate and methyl palmitoleate.

\section{Conclusions}

A nontoxic and reusable supported catalyst was formulated by an incipient wetness impregnation of alumina with eggshell. The prepared ASE catalyst with the BET surface area and basicity of $78.2 \mathrm{~m}^{2} / \mathrm{g}$ and $1.88 \mathrm{mmol} / \mathrm{g}$ cat, respectively, exhibited a better performance in the transesterification of the WFO with methanol to biodiesel. An investigation of the effects of the transesterification process variables on the biodiesel yield revealed that the reaction time contributed the most to the biodiesel production process, as much as $40.139 \%$, while the catalyst loading contributed the least to the process, as low as $1.233 \%$. The interaction between the reaction time and the reaction temperature had the most significant effect on the biodiesel yield, compared to other interaction terms. A maximum biodiesel yield was obtained under the optimized factor combination of $4.0 \mathrm{wt} . \%$ catalyst loading, $120 \mathrm{~min}$ reaction time, $12: 1$ methanol/oil molar ratio and reaction temperature of $65^{\circ} \mathrm{C}$. The reduction in the catalyst performance after four cycles of reaction was noticed, indicating a loss of active sites.

\section{REFERENCES}

[1] Abdulkareem, A.S., Uthman, H., Afolabi, A.S., \& Awenebe, O.L. (2011). Extraction and optimization of oil from moringa oleifera seed as an alternative feedstock for the production of biodiesel, sustainable growth and applications in renewable energy sources, Dr. Majid Nayeripour (Ed.), ISBN: 978-953-307-408-5, Intech.

[2] Fabbri, D., Bevoni, Notari, M., \& Rivetti, F. (2007). Properties of a potential biofuel obtained from soybean oil by transmethylation with dimethyl carbonate. Fuel, 86(5/6), 690-697. DOI:10.1016/j.fuel.2006.09.003.

[3] Furuta, S., Matsuhashi, H., \& Arata, K. (2004). Biodiesel fuel production with solid super acid catalysis in fixed bed reactor under atmospheric pressure. Catalysis Communication, 5(12), 712-723. DOI:10.1016/j.catcom.2004.09.001.

[4] Granados, M.L., Poves, M.D.Z., Alonso, D.M., Mariscal, R., Galisteo, F.C., Moreno-Tost R., Santamaria, J., \& Fierro, J.L.G. (2009). Biodiesel from sunflower oil by using activated calcium oxide. Applied catalysis B: Environmental, 73(3-4), 317-326. DOI:10.1016/j.apcatb.2006.12.017.

[5] Jitputti, J., Kitiyanan, B., Bunyakiat, K., Rangsunvigit, P., \& Jakul, P.J. (2006).

Transesterification of crude palm kernel oil and crude coconut oil by different solid catalysts. Chemical Engineering Journal, 116(1), 61-66. DOI:10.1016/j.cej.2005.09.025.

[6] Leung, D.Y.C., Guo, Y. (2006). Transesterification of neat and used frying oil: Optimization for biodiesel production. Fuel Processing Technology, 87, 883-890. DOI:10.1016/j.fuproc.2006.06.003. 
[7] Mbaraka, I.K., \& Shanks, B.H. (2006). Conversion of oils and fats using advanced mesoporous heterogeneous catalysts. Journal of the American Oil Chemists' Society, 83, 79-91. DOI:10.1007/s11746-006-1179-x.

[8] Olutoye, M.A \& Hameed, B.H., (2013). A highly active clay-based catalyst for the synthesis of fatty acid methyl ester from waste cooking palm oil". Applied Catalysis A: General. 450, 57-62. DOI:10.1016/j.apcata.2012.09.049.

[9] Olutoye, M.A., Wong, S.W., Chin, L.H., Asif, M., \& Hameed, B.H. (2016). Synthesis of fatty acid methyl esters via transesterification of waste cooking oil by methanol with a barium-modified montmorillonite K10 catalyst. Renewable Energy, 86, 392-398. DOI:10.1016/j.renene.2015.08.016.

[10] Olutoye, M.A., Adeniyi, O.D, \& Yusuff, A.S, (2016). Synthesis of biodiesel from palm kernel oil using mixed clay-eggshell heterogeneous catalysts. Iranica Journal of Energy and Environment, 7(3), 308-314. DOI:10.5829/idosi.ijee.2016.07.03.14.

[11] Paintsil, A. (2013). Optimization of the transesterification stage of biodiesel production using statistical methods. A Msc. thesis, school of graduate and postgraduate studies, University of Western Ontario, Canada.

[12] Refaat, A.A. (2011). Biodiesel production using solid metal oxide catalyst. International Journal of Environmental Science and Technology, 8(1), 203-221. DOI:10.1007/BF03326210.

[13] Shuit, S.H., Yit, T.O., Keat, T.L., Bhatia, S., Soon, H.T. (2012). Membrane technology as a promising alternative in biodiesel production: A review. Biotechnology Advances, 30(6), 1364-1380. DOI:10.1016/j.biotechadv.2012.02.009.
[14] Tan, Y.H., Abdullah, M.O., Hipolito, C.N., \& TaufiqYap., Y.H. (2015). Waste ostrich and chicken-eggshells as heterogeneous base catalyst for biodiesel production from used cooking oil: catalyst characterization and biodiesel yield performance. Applied Energy, 2, 1-13. DOI:10.1016/j.apenergy.2015.09.023.

[15] Taufiq-Yap, Y.H., Abdullah, N.F., \& Basri, M. (2011). Biodiesel production via transesterification of palm oil using $\mathrm{NaOH} / \mathrm{Al}_{2} \mathrm{O}_{3}$ catalysts. Sains Malaysiana, 40(6): 587-594.

[16] Umdu, E.S., Tuncer, M., \& Seker, E. (2009). Transesterification of nannochloroplasts oculata microalga's lipid to biodiesel on $\mathrm{Al}_{2} \mathrm{O}_{3}$ supported $\mathrm{CaO}$ and $\mathrm{MgO}$ catalysts. Bioresources Technology, 100, 2828-2837. DOI:10.1016/j.biotech.2008.12.027.

[17] Yee, K.F., \& Lee, K.T. (2008). Palm oil as feedstock for biodiesel production via heterogeneous transesterification: Optimization Study. International Conference on Environment (ICENV), 1-5.

[18] Yusuff, A.S., Adeniyi, O.D., Olutoye, M.A., \& Akpan, U.G. (2017). A review on Application of heterogeneous catalyst in the production of biodiesel from vegetable oils. Journal of Applied Science and Process Engineering, 4(2), 142-157.

[19] Yusuff, A.S., Adeniyi, O.D., Olutoye, M.A., \& Akpan, U.G. (2018). Development and characterization of a composite anthill-eggshell catalyst for biodiesel production from waste frying oil. International Journal of Technology, 1, 110-119. DOI:10.14716/ijtech.v9i1.1166.

[20] Yusuff, A.S., Adeniyi, O.D., Azeez, O.S., Olutoye, M.A., Akpan, U.G. (2019). Synthesis and characterization of anthill-eggshell-Ni-Co mixed oxides composite catalyst for biodiesel production from waste frying oil. Biofuels, Bioproducts $\&$ Biorefining, 13, 37-47; DOI:10.1002/bbb.1914 